\title{
Optimization of the Operational Conditions for the Treatment of Reactive Dyes through a Statistical Tool: Response Surface Methodology
}

\author{
Sonalika Sonal and Brijesh Kumar Mishra
}

\begin{abstract}
The present research focused on the optimization of coagulation process parameters by using iron-based coagulant for the treatment of most recalcitrant reactive dye i.e. Reactive Blue 19. The manual traditional methods of optimization and Central Composite Design (CCD) using RSM were applied to optimize three operating variables of coagulation/flocculation process including initial $\mathrm{pH}$, coagulant dosage and initial dye concentration. The results obtained by using RSM software showed more relevant and specific results as compared with the traditional method. The RSM result shows that an increase in $\mathrm{pH}$ was beneficial for enhancing dye removal, up to a certain level but the further increment in $\mathrm{pH}$, resulted in a decrease in dye removal. Decolorization of RB19 has been improved with increasing coagulant dose but its concentration in the treated water also increased as they showed more prominent oxidized color, when comes in contact with air. The optimum conditions found by RSM was most appropriate and accurate as compared to that of the traditional method. The optimum conditions i.e. initial pH, coagulant dosage and initial dye concentration were found to be 7.3 , $234.82 \mathrm{mg} / \mathrm{L}$ and $150 \mathrm{mg} / \mathrm{L}$, respectively for dye removal of $83.45 \%$. The test proved that RSM would be a good tool for the optimization process of parameters. Though ferric chloride gave better results as coagulant still presence of higher concentration of iron in the effluent can have adverse effects, that can be further evaluated.
\end{abstract}

Index Terms-Coagulation/flocculation, dye removal, ferric chloride, response surface design.

\section{INTRODUCTION}

The deterioration in the quality of water is mainly due to the anthropogenic activities, population growth, unplanned urbanization, rapid industrialization and unskilled utilization of natural water resources. Industrialization plays an important role in the development of any country and textile industry is one of the vast emerging industrial segments. Dyeing is the most crucial treatment unit in the textile industry, involved mainly in coloration of fabric or yarn with a dye [1] and is the main creator of effluent wastewater due to its huge consumption of water for its various wet processing operations. These effluents contain chemicals such as acids, alkalis, residual dyes, hydrogen peroxide, starch, surfactants dispersing agents etc. India is one of the major manufacturers of textiles and hence it can be said that India is the major

Manuscript received November 5, 2018; revised April 15, 2019.

Sonalika Sonal and Brijesh Kumar Mishra are with the Department of Environmental Science and Engineering, Indian Institute of Engineering (Indian School of Mines), Dhanbad, Jharkhand, India (e-mail: brijesh@iitism.ac.in). contributor of textile wastewater in South Asia [1]. At present most, common types of dyes used in textile industries are fall in the group of aromatic and heterocyclic dyes and their stable structures possess greater difficulty in their degradation [2].

The effluent wastewater can be treated by physical, chemical and biological methods. Physical and chemical methods include adsorption, biosorption, sedimentation, deep bed filters, coagulation/flocculation, electro-coagulation, denitrification, photo catalytic reduction etc. [3]. Coagulation of dye-containing wastewater has been used for many years as main treatment or pre-treatment due to its low capital cost, high efficiency and simple operation [3]. Coagulants based on hydrolyzing metal salts such as aluminium and iron are widely used as a coagulant. Ferric chloride $(\mathrm{FC})$ has been widely used in water treatment due to its good performance on turbidity and TOC removal [4], as compared to aluminium-based coagulant at a lower dosage. The metal salts hydrolyze rapidly, that are adsorbed by negatively charged particles and cause charge reduction. Earlier, the coagulation process's parameters were optimized by using traditional hit and trial method that does not give exactly optimum points for the treatment of dye wastewater. Recently a new statistical tool, Response Surface Methodology (RSM) has been used to optimize various parameters required for the different treatment process [5], [6]. Basically, RSM is a collection of mathematical and statistical techniques that are useful for the optimization of chemical reactions and are mostly used for experimental designs [6]

Hence, in this study, a comparative study was commenced for evaluation of the effectiveness of a well-known coagulant (ferric chloride) for the removal of Remazol Brilliant Blue $\mathrm{R}$ using traditional method and by a statistical tool, named RSM (Response surface methodology).

\section{MATERIALS AND METHODS}

\section{A. Chemical and Materials}

An anthraquinone based dye Reactive Blue 19 (Sigma Aldrich) was chosen as a representative reactive dye and was supplied by Sigma Aldrich, USA. The characteristics of the dye are given in Table I. Other chemical reagents such as Ferric chloride, Hydrochloric acid, Sodium hydroxide etc., were purchased from Merck, Mumbai, India. Milli-Q RO water (Millipore, USA) was used for the preparation of the stock solution and other samples preparation as per the experimental requirement. In this study, all reagents used 
were of analytical grade and used without further pre-treatment. A stock solution of dye mass was prepared in mili-Q RO water to a desirable concentration and diluted accordingly to the working concentrations. A stock solution of coagulant was prepared at a desirable concentration freshly every day. The required $\mathrm{pH}$ was adjusted by using $1 \mathrm{~N}$ $\mathrm{NaOH}$ and $1 \mathrm{~N} \mathrm{HCl}$. pH was measured by using a $\mathrm{pH}$ meter (Hanna Instrument).

TABLE I: CHARACTERIZATION OF DYE

\begin{tabular}{|l|l|l|l|l|}
\hline $\begin{array}{l}\text { Name of } \\
\text { the dyes }\end{array}$ & $\begin{array}{l}\Lambda_{\max } \\
(\mathrm{nm})\end{array}$ & $\begin{array}{l}\text { Purity } \\
(\%)\end{array}$ & Type of dye & $\begin{array}{l}\text { Molecular } \\
\text { weight }\end{array}$ \\
\hline $\begin{array}{l}\text { Reactive } \\
\text { Blue 19 }\end{array}$ & 596 & $\sim 50 \%$ & Reactive & $\begin{array}{l}626.54 \mathrm{gm} / \\
\text { mol }\end{array}$ \\
\hline
\end{tabular}

\section{B. Experimental Method}

Jar beakers of one-litre volume were filled with the required concentration of the dye solution and $\mathrm{pH}$ was adjusted to optimized $\mathrm{pH}$ accordingly using $0.1 \mathrm{~N} \mathrm{HCl}$ and $\mathrm{NaOH}$. After a while, the optimized dose of the coagulant dose was added to each beaker. A standard digital six jar test apparatus (Labard Instru Chem India) equipped with stainless steel paddles was used to perform the coagulation/flocculation process. The coagulation/flocculation procedure involved $2 \mathrm{~min}$ of rapid mixing at $200 \mathrm{rpm}$, followed by $30 \mathrm{~min}$ of slow mixing at 40 rpm, and $120 \mathrm{~min}$ of settling time. After settling the supernatant liquid was withdrawn from each beaker by using water syringe from a height of about $2 \mathrm{~cm}$ below the liquid surface. Then the dye concentration was measured using UV/ Vis spectrophotometer (Labtech, Model: UV 9100/A) at the maximum wavelength of the dye i.e. at $595 \mathrm{~nm}$. The dye concentration was calculated by using the standard curve and dye removal percentage was calculated by using the following formula:

$$
\text { Dye Removal }(\%)=\frac{C_{o}-C_{f}}{C_{o}} 100
$$

where $C_{0}$ and $C_{f}$ are the initial and final dye concentration respectively.

\section{Experimental Design and Data Analysis}

Experimental design of the process for removal of Remazol Brilliant Blue R was carried out by using traditional and as well as design expert optimization method. The main objective of using the traditional optimum method and RSM is to determine the optimum operational conditions for the system that satisfies the operating specifications [6,7]. The effect of three variables in the coagulation/ flocculation process including the initial $\mathrm{pH}$ of the solution, coagulant dosage and initial dye concentration was examined. In case of the traditional optimization process, the variables were optimized one by one while for RSM, each independent variable was varied over three levels between -1 and +1 at the determined ranges based on some preliminary experiments as shown in Table II.

Prior to initiating the experiments, a foremost preliminary experiment was conducted to determine a narrow range of $\mathrm{pH}$, dye concentration and coagulant dosage. For this purpose, experiments were carried out by varying a single factor while keeping all other factors fixed at a specific set of conditions. For RSM, range and level were selected based on preliminary experiments then, experimental data was analysed and fitted to a second-order polynomial model to optimize the variables in the coagulation/ flocculation process. The quadratic equation model for predicting the optimal conditions can be expressed as Eq. (2)

$$
Y=b_{0}+\sum_{i=1}^{n} \text { bixi }+\sum_{i=1}^{n} \text { biixi } 2+\sum_{i=1}^{n-1} \sum_{j=i+1}^{n} \text { biijxixj }
$$

where, $Y$ is the predicted response (dye removal efficiency), $\mathrm{b}_{0}$ the constant coefficient, bi the linear coefficients, bii the quadratic coefficients, bij the interaction coefficients and xi, $\mathrm{xj}$ are the coded values of the variables. The quality of the fit polynomial model was expressed by the coefficient of determination $R^{2}$. The $R^{2}$ values provide a measure of how much variability in the observed response values can be explained by the experimental factors and their interactions.

TABLE II: EXPERIMENTAL RANGE AND LEVELS OF INDEPENDENT PROCESS VARIABLES FOR REMAZOL BRILLIANT BLUE R BY USING STAT DESIGN

\begin{tabular}{|l|l|l|l|l|}
\hline \multirow{2}{*}{$\begin{array}{l}\text { Independent } \\
\text { Variables }\end{array}$} & \multirow{2}{*}{ Unit } & \multicolumn{4}{|l|}{ Range and level } \\
\cline { 3 - 5 } & & -1 & 0 & +1 \\
\hline $\mathrm{pH}$ & - & 6 & 7 & 8 \\
\hline Coagulant Dose & $\mathrm{mg} / \mathrm{L}$ & 200 & 240 & 280 \\
\hline Dye Concentration & $\mathrm{mg} / \mathrm{L}$ & 50 & 100 & 150 \\
\hline
\end{tabular}

These analyses are done by means of Fisher's ' $F$ ' test and $\mathrm{P}$-value (probability). Model terms were evaluated by the P-value with a 95\% confidence level. Finally, the optimal values of the critical parameters were obtained by analysing the surface and counterplots and also by solving the regression equations.

\section{RESUlTS AND DisCUSSION}

\section{A. Optimization of the Process Using the Traditional Method}

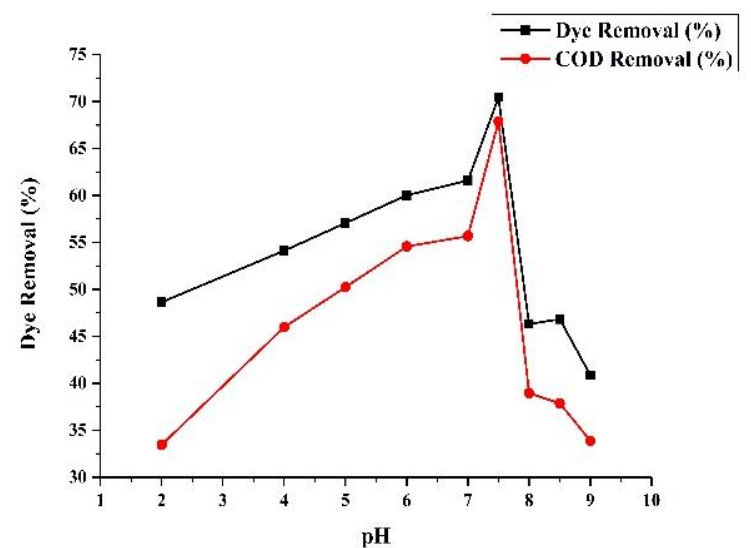

Fig. 1. Optimization of $\mathrm{pH}$, keeping dose and dye concentration constant at $100 \mathrm{mg} / \mathrm{L}$.

The traditional optimization method was carried out by varying one parameter and keeping other parameters constant. The Fig. 1,2 \& 3 represented the different parameters' optimization process. The results show that the $\mathrm{pH} 7.5$ shows better results as compared to that of other acidic or alkaline $\mathrm{pH}$. In the case of dose, the results clearly show that as the 
dose increases the removal efficiency increases but after certain extent, it goes down as the excess of doses may cause re-stabilization of the colloids [7]. Similarly, the increasing dye concentration also tends to decreases in removal efficiency, because of high load on coagulant that makes them insufficient to removes the dye from the bulk medium. Based on the above optimization process, the optimum condition obtained was used for one confirmatory experiment.

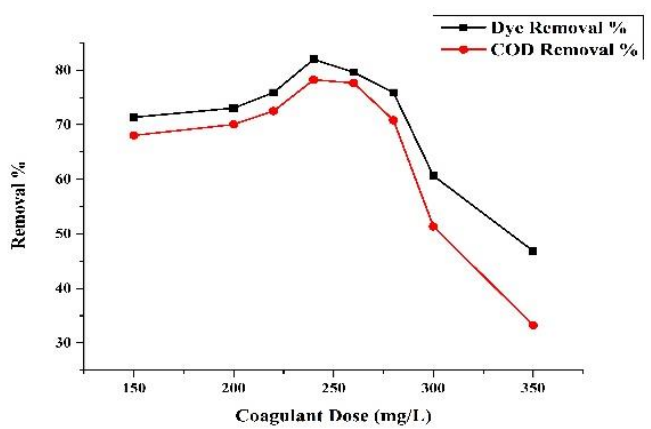

Fig. 2. Optimization of coagulant dose by keeping $\mathrm{pH} 7.5$ and dye concentration $100 \mathrm{mg} / \mathrm{L}$.

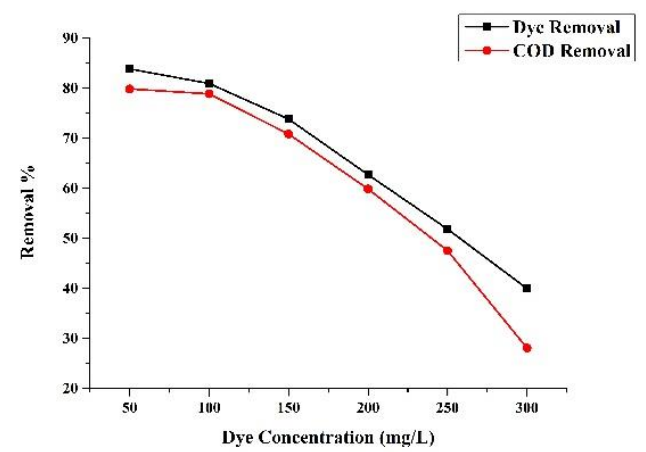

Fig. 3. Optimization of dye concentration by keeping $\mathrm{pH} 7.5$ and dose at $240 \mathrm{mg} / \mathrm{L}$

\section{B. RSM Optimization: Development of Regression Model Equation and Validation of the Model by ANOVA}

To study the combined effect of three variable factors, experiments were performed at different combinations of the physical parameters using statistical experiments. The application of RSM offers an empirical design to relate the response and test variables based on parameter estimation. Table III represented the analysis of variance (ANOVA) of regression parameters of the predicted response surface quadratic model for dye removal efficiency in the effluent. High $\mathrm{R}^{2}$ value illustrates good agreement between the calculated and observed results within the range of experiment. Values of $P>F$ less than 0.05 indicate that model terms are significant, while values greater than 0.100 indicate that the model terms are not significant.

The final regression model, in terms of their coded factors, has been expressed by the following second order polynomial equations-

Dye removal $(\%)=+87.52-4.40 \mathrm{~A}+2.48 \mathrm{~B}+7.87 \mathrm{C}-0.92 \mathrm{AB}$ $+13.13 \mathrm{AC}-0.053 \mathrm{BC}-8.01 \mathrm{~A}^{2}-5.16 \mathrm{~B}^{2}-5.14 \mathrm{C}^{2}$

A positive sign in front of terms indicates synergistic effect and negative sign implies the antagonistic effect. For a model to be reliable, the response should be predicted with a reasonable accuracy by the model when compared with experimental data and in the present study for all the responses, the predicted and experimental values show close linearity with each other suggesting a good agreement between them (Fig 4 (a)).

TABLE III: ANOVA RESULTS FOR RESPONSE SURFACE QUADRATIC MODEL ANALYSIS OF VARIANCE

\begin{tabular}{|l|l|l|l|l|l|l|}
\hline Response & Source & $\begin{array}{l}\text { Sum of } \\
\text { square }\end{array}$ & $\begin{array}{l}\text { Degree of } \\
\text { freedom }\end{array}$ & $\begin{array}{l}\text { Mean } \\
\text { square }\end{array}$ & $\begin{array}{l}F \\
\text { value }\end{array}$ & $P>F$ \\
\hline $\begin{array}{l}\text { Dye } \\
\text { removal }\end{array}$ & Model & 3501.96 & 9 & 389.11 & 70.18 & $<0.0001$ (Significant) \\
\cline { 2 - 7 } & Residual & 55.45 & 10 & 5.54 & & \\
\cline { 2 - 7 } & $\begin{array}{l}\text { Lack of } \\
\text { fit }\end{array}$ & 44.92 & 5 & 8.98 & 4.27 & $\begin{array}{l}0.0686 \text { (Not- } \\
\text { significant) }\end{array}$ \\
\cline { 2 - 7 } & $\begin{array}{l}\text { Pure } \\
\text { Error }\end{array}$ & 10.52 & 5 & 2.10 & & \\
\hline S.D=2.35, Press=365.22, $R^{2}=0.9844$, Adj. $R^{2}=0.9704$ \\
\hline \\
\hline
\end{tabular}

Further, the model result was validated by ANOVA results, that suggests the significance of model with non- significant lack of fit (Table III). Further, the interrelation between factors was also assessed with the help of 3D surface graphs.

The results showed that the highest removal efficiency was obtained at $\mathrm{pH} 7.5$ at a dose of $240 \mathrm{mg} / \mathrm{L}$ for the dye concentration of $100 \mathrm{mg} / \mathrm{L}$. Since reactive dyes are in the anionic category as the functional groups in these dyes contain anionic groups such as sulfonic, hydroxyl and amine, which leads to carried negative charged by dissolving in water. For coagulation, their negative charge gets neutralized with positively charged ferric ions with greater severity at $\mathrm{pH}$ 7.5.

In Fig 4 (b) it was observed that the removal efficiency of dye increases as the $\mathrm{pH}$ increases till 7.5 and after that, it decreases. The efficiency follows the same trend for the coagulant dose, at the optimum dose it shows maximum removal.

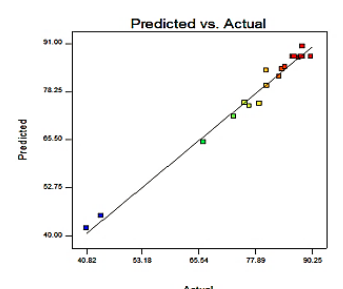

(a)

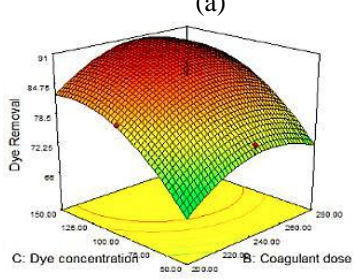

(c)

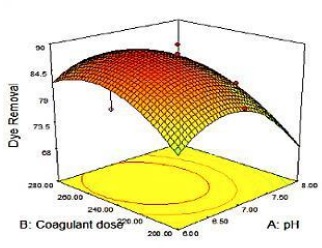

(b)

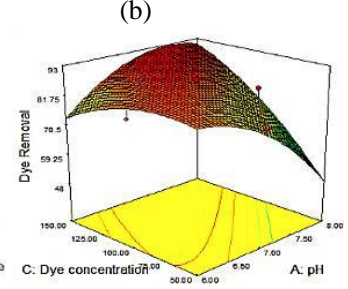

(d)
Fig. 4. Design expert graph showing (a) Pred. vs Actual values and (b, c \& d) interaction of independent variables with respect dye removal $(\%)$. 


\section{Optimization}

Through the classic and statistical model, the optimized parameters were obtained with predicted values and the results were further validated with the experimental data (Table IV). The result shows that in the case of the traditional method the best-optimized results, are not that much accurate in comparison with the optimized results obtained through the RSM. The possible reason behind this may be because of the advantage of RSM over Traditional method. In RSM the optimization has been achieved through the combined effect of independent variables with the response as well as with other factors also. Thus, in the case of RSM, both experimental and predicted results have a close relation with each other which suggest experimental validation of the experimental design.

TABLE IV: OPTIMUM VALUES FOR DECOLORIZATION OF REACTIVE BLUE

\begin{tabular}{|l|l|l|l|}
\hline Variables & Unit & $\begin{array}{l}\text { Optimum } \\
\text { Values using } \\
\text { the } \\
\text { traditional } \\
\text { method }\end{array}$ & $\begin{array}{l}\text { Optimum } \\
\text { Values } \\
\text { using } \\
\text { RSM }\end{array}$ \\
\hline $\begin{array}{l}\text { Initial pH of the dye } \\
\text { solution (A) }\end{array}$ & - & 7.5 & 7.30 \\
\hline Coagulant dose (B) & $\mathrm{mg} / \mathrm{L}$ & 240 & 234.82 \\
\hline $\begin{array}{l}\text { Initial Dye Concentration } \\
\text { (C) } \mathrm{mg} / \mathrm{L}\end{array}$ & 50 & 150 \\
\hline $\begin{array}{l}\text { Dye removal efficiency } \\
\text { (predicted) }\end{array}$ & $\%$ & 83.47 & 85.15 \\
\hline $\begin{array}{l}\text { Dye removal } \\
\text { efficiency(experimental) }\end{array}$ & $\%$ & 80.56 & 83.45 \\
\hline
\end{tabular}

\section{CONCLUSION}

In this research, the coagulation/flocculation process was studied to remove Remazol Brilliant Blue R by using Ferric Chloride $(\mathrm{FeCl} 3)$ as a coagulant. The operational parameters for the coagulation/flocculation parameters were optimized by using two methods i.e. traditional and a statistical optimization method (a central composite design coupled with response surface methodology). The results clearly showed that RSM overcomes the limitations of classical methods and was successfully employed to obtain the optimum process conditions along with the interactions between process variables. Hence, it should be worthy to mention that RSM, must be an effective tool for optimizing the operational parameters for coagulation/flocculation process, although a preliminary result based on traditional methods were also be required for its initial range of independent variables validation.

\section{ACKNOWLEDGMENT}

The authors are grateful to the Department of
Environmental Science and Engineering and of Indian Institute of Technology (ISM) Dhanbad, India for providing the facilities and technical support.

\section{REFERENCES}

[1] C. R. Holkar et al., "A critical review on textile wastewater treatments: possible approaches," Journal of Environmental Management, vol. 182, pp. 351-366, 2016.

[2] S. Ding, Z. Li, and R. Wang, "Overview of dyeing wastewater treatment technology," Water Resour Prot, vol. 26, pp. 73-78, 2010.

[3] T. K. F. S. Freitas et al., "Optimization of a coagulation-flocculation process for treatment of industrial textile wastewater using okra (A. esculentus) mucilage as natural coagulant," Industrial Crops and Products, vol. 76, pp. 538-544, 2015.

[4] Y. Shi et al., "Comparison of corrosivity of polymeric sulfate ferric and ferric chloride as coagulants in water treatment," Chem. Eng. Process. Process Intensif., vol. 43, pp. 955-64, 2004.

[5] S. S. Moghaddam, M. A. Moghaddam, and M. Arami, "Coagulation/flocculation process for dye removal using sludge from water treatment plant: optimization through response surface methodology," Journal of Hazardous Materials, vol. 175, no. 1-3, pp/ 651-657, 2010.

[6] M. Khayet, A. Y. Zahrim, and N. Hilal, "Modelling and optimization of coagulation of highly concentrated industrial grade leather dye by response surface methodology," Chem. Eng. J., vol. 167, pp. 77-83, 2011.

[7] S. Sonal, A. Singh, and B. K. Mishra, "Decolorization of reactive dye Remazol Brilliant Blue $\mathrm{R}$ by zirconium oxychloride as a novel coagulant: optimization through response surface methodology," Water Science and Technology, vol. 78, no. 2, pp. 379-389, 2018.

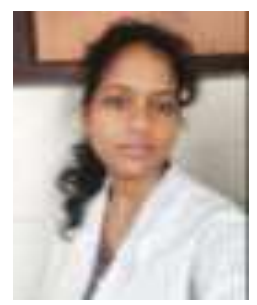

Sonalika Sonal is a senior research fellow in the Department of Environmental Science and Engineering, at IIT (ISM) Dhanbad, Jharkhand, India. She was born on Aug. 17, 1993, Muzaffarpur, India. She has completed her B.Sc. and M.Sc. from Patna University in the field of zoology and environmental science respectively. Currently, she is doing her $\mathrm{PhD}$ from IIT (ISM) Dhanbad and currently working in the field of wastewater treatment through coagulation/flocculation process, development of materials (adsorbent) for the development of hybrid technology for the treatment of dye wastewater.

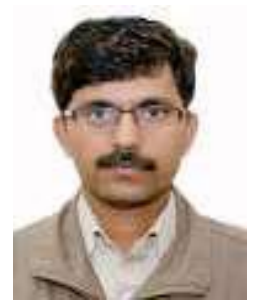

Brijesh Kumar Mishra is an assistant professor, in the Department of Environmental Science and Engineering at Indian Institute of Technology (Indian School of Mines) Dhanbad, Jharkhand, India. He was born on $6^{\text {th }}$ July 1980 in Uttar Pradesh, India. He has completed his B. Tech and M. Tech degree from AAI and MNNIT, UP in the field of agricultural science and environmental Science respectively. He has completed his Doctorate degree from IIT (ISM) Dhanbad. He has more than 8 years of teaching experience and has been extensively working in the field of treatment of Water and Wastewater by the physical and chemical method, exposure and human health risk assessment, enhanced coagulation process, development of low-cost adsorbent, in-situ remediation of soil/sludge by physical and chemical method etc. He is an active member of different Professional bodies such as Indian Water Works Association and The Mining, Geological and Metallurgical Institute of India. 